\title{
Fascia iliaca compartment block versus no block for pain control after lower limb surgery: a meta-analysis
}

This article was published in the following Dove Press journal: Journal of Pain Research

\section{Linyi Yang \\ Min Li \\ Chen Chen \\ Jiang Shen \\ Xiaoxuan Bu}

Department of Anesthesiology, The Third Affiliated Hospital of Soochow University, Changzhou, China
Correspondence: Xiaoxuan Bu Department of Anesthesiology, The Third Affiliated Hospital of Soochow University, 185 Juqian Street, Changzhou 213003, Jiangsu Province, China

Tel +865 I96 8870000

Email xiaoxuanbu@।26.com
Background: The analgesic effect of fascia iliaca compartment block (FICB) versus no block (NB) after lower limb surgery (LLS) is still controversial, so we performed this meta-analysis. Materials and methods: By searching the PubMed, Embase and the Cochrane Library (last update by July 20, 2017), randomized controlled trials comparing the analgesic effect of FICB versus NB in patients receiving LLS were identified. The primary outcome was the pain scores at 4,12 , and $24 \mathrm{~h}$ after LLS. The dosage of morphine at $24 \mathrm{~h}$ was also collected. The side effect of anesthesia was assessed according to the occurrence rate of postoperative nausea and vomiting. Results: Data from 7 clinical trials that included 508 patients were summarized. The results showed that patients receiving FICB had lower pain scores at $4 \mathrm{~h}$ (mean difference $[\mathrm{MD}]=-1.17$; $95 \% \mathrm{CI}=-2.30$ to $-0.05 ; P=0.041), 12 \mathrm{~h}(\mathrm{MD}=-0.41 ; 95 \% \mathrm{CI}=-0.76$ to $-0.05 ; P=0.026)$ and 24 $\mathrm{h}(\mathrm{MD}=-0.96 ; 95 \% \mathrm{CI}=-1.77$ to $-0.15 ; P=0.020)$ after LLS. Besides, FICB could reduce the dosage of morphine at $24 \mathrm{~h}(\mathrm{MD}=-2.06 ; 95 \% \mathrm{CI}=-3.82$ to $-0.30 ; P=0.022)$ and the incidence of postoperative nausea and vomiting (relative risk rate $=0.44,95 \% \mathrm{CI}=0.24-0.80, P=0.008$ ). Conclusion: Compared with NB, FICB is an effective and safe method for alleviating the pain after LLS. More high-quality randomized controlled trials are needed to confirm this finding.

Keywords: fascia iliaca compartment block, lower limb surgery, meta-analysis, RCTs

\section{Introduction}

Lower limb surgery (LLS), especially in the region of medial thigh, and front and lateral and knee, is usually performed to relieve joint pain, correct deformity, and improve motor function of the joint. ${ }^{1}$ For patient to receive LLS, postoperative pain is the first symptom. Due to the physical symptoms and psychological pressure, patients focus on pain, which aggravates the degree of pain. Severe pain after LLS can affect a patient's mood and result in failure to complete the postoperative exercise, which may limit functional recovery. ${ }^{2}$ Some studies have revealed that the fascia iliaca compartment block (FICB) could provide an analgesic effect in patients with femur fractures. ${ }^{3-5}$ They concluded that the FICB is an effective and easily learned procedure to decrease postoperative pain score and dosage of opioid.

FICB is a peripheral nerve block, which has become an important part of postoperative multimodal analgesic strategies. FICB was first reported by Dalens et al. ${ }^{6}$ As an alternative to the 3-in-1 nerve block, it is now one of the major methods of lower limb nerve block and is widely used in postoperative analgesia in patients after LLS. ${ }^{6}$ More specifically, the femoral, lateral femoral cutaneous, and obturator nerves of the thigh are blocked by local anesthetic (LA) injected under the fascia of iliacus 
muscle (Figure 1). ${ }^{6-8}$ The pain block can persist up to 24 h. ${ }^{9,10}$ However, the pop technique using fascial click had a low success rate of $35 \%-47 \%$. ${ }^{11}$ When FICB was performed under real-time ultrasound guidance, the success rate increased to $82 \%-87 \%$, which led to an increased interest in FICB as a postoperative analgesia option for hip and knee surgeries. ${ }^{12}$

However, some studies have showed that FICB is inefficacious in reducing pain scores and dosage of opioid in patients after hip arthroplasty. ${ }^{13}$ Therefore, it is necessary to conduct a meta-analysis to evaluate the efficacy and safety of FICB in alleviating pain after LLS, which is helpful for postoperative rehabilitation.

\section{Materials and methods}

This meta-analysis was carried out in accordance with the Systematic Reviews and Meta-Analyses (PRISMA) guidelines ${ }^{14}$ and the Observational Studies in Epidemiology (MOOSE) guidelines. ${ }^{15}$ The data included in our study did not require informed patient consent, and our study was approved by the Ethical Committee and Institutional Review Board of Soochow University.

\section{Search strategy}

Literature was searched through PubMed, Embase and the Cochrane Library (last update on July 20, 2017). Keywords used in the search strategy were "fascia iliaca OR fascia iliaca compartment block" (all fields) AND "randomized OR randomised" (all fields) AND "surgery" (all fields). The language was limited to English only. We did not impose any advanced limitations in the database searching process. Besides title, abstract and full text, all the reference lists of identified articles were also screened to further identify potential studies. The comprehensive database search and availability evaluation were carried out independently by 2 authors (LY and ML). Disagreement from 2 reviewers was resolved via a third reviewer.

\section{Inclusion and exclusion criteria}

To be eligible for inclusion in this meta-analysis, literature was required to meet the following criteria: 1) randomized controlled trials (RCTs) comparing methods of nerve block in patients undergoing LLS; 2) FICB versus no block (NB); and 3 ) the primary outcome measure was postoperative pain scores. The exclusion criteria were as follows: 1) when multiple studies were targeted at the same patient cohort, only the most recent or complete study was selected; 2) case reports, letters, reviews, conference abstracts and animal trials were excluded; 3) studies without comparable groups; and 4) data couldn't be extracted.

\section{Data extraction and quality assessment}

The required parameters from all eligible studies were collected by 2 researchers independently, which included first author's surname, publication year, country, study characteristics (number of patients and percent of female patients), and participant characteristics (i.e., mean age, body mass index, technique of FICB, complication of FICB, nature of study, type of standard care, operative type, and LA). The main outcome was the postoperative pain score. If additional information and original data were needed for the meta-analysis, we sent e-mail to the corresponding authors of eligible articles. Data in other forms (i.e., median, interquartile range, and mean $\pm 95 \% \mathrm{CI}$ ) were converted to mean $\pm \mathrm{SD}$, as described in the Cochrane handbook. ${ }^{16}$ If the data were not reported

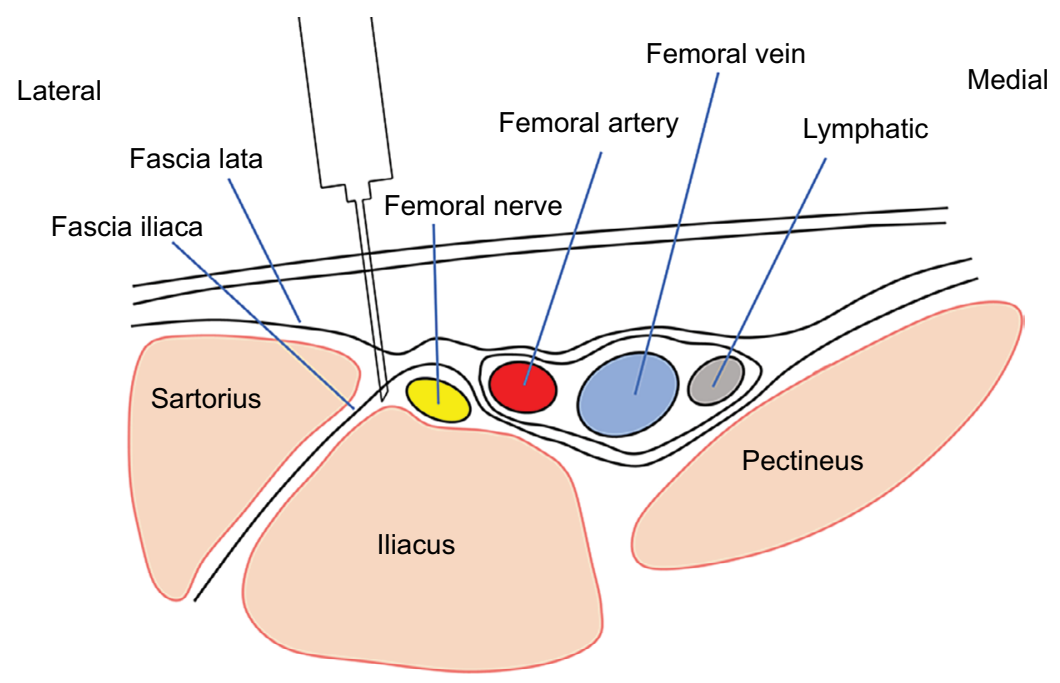

Figure I Anatomy of the fascia iliaca compartment block. 
numerically, we extracted them from the published figures using the "Get Data Graph Digitizer" software. ${ }^{17}$

The quality of individual studies was evaluated using the Downs and Black quality assessment method, which is a list of 27 criteria to evaluate both randomized and nonrandomized trials. ${ }^{18}$ This quality assessment scale (QAS) assesses study reporting, external validity, and internal validity (i.e., bias and confounding), and has been ranked in the top 6 QAS suitable for use in systematic reviews. ${ }^{19,20}$ As has been done in other reviews using the Downs and Black scale, ${ }^{21,22}$ the tool was modified slightly for use in this review. Specifically, the scoring for question 27 dealing with statistical power was simplified to a choice of awarding either 1 or 0 point depending on whether there was sufficient power to detect a clinically important effect. Downs and Black score ranges were grouped into the following 4 quality levels: excellent (26-28), good (20-25), fair (15-19), and poor $(<14)$.

Two reviewers (LY and ML) independently assessed the quality of the included studies. A consensus method was used to resolve disagreement.

\section{Statistical analysis}

Continuous outcomes, such as the postoperative pain scores at 4,12 , and $24 \mathrm{~h}$, dosage of morphine at $24 \mathrm{~h}$, and surgery time, were expressed as the mean difference (MD) with the respective $95 \%$ CIs. Discontinuous outcome (the rate of postoperative nausea and vomiting [PONV]) was expressed as the relative risk (RR) with $95 \%$ CIs. Statistical heterogeneity was assessed by visual inspection of forest plots, by performing the Chi-square test (assessing the $P$-value), and by calculating the $I^{2}$ statistic. ${ }^{23,24}$ If the $P$-value was $<0.05$ and/or $I^{2}$ exceeded $50 \%$, indicating the presence of heterogeneity, a randomeffects model (the DerSimonian-Laird method) was used. Otherwise, the fixed-effects model (the Mantel-Haenszel method) was used. Publication bias was estimated using Egger's and Begg's tests. If publication bias was observed, we adjusted for the effect by using the Duval and Tweedie trim-and-fill method. ${ }^{25}$ Sensitivity analysis was conducted to further identify potential sources of heterogeneity. For all analyses, STATA version 12.0 (Stata Corporation, College Station, TX, USA) was used with significance defined as a $P$-value $<0.05$ except where otherwise specified.

\section{Results}

\section{Study characteristics}

A total of 60 studies were initially enrolled based on the search strategy. After viewing the contents of each article, 15 studies compared the effects of different types of nerve blocks. Among these, 8 articles that only compared FICB with other types of nerve blocks were excluded. Finally, 7 articles were found eligible for review (Figure 2), ${ }^{4,13,26,27,29-31}$

Of the 7 articles, 1 study each was carried out in Australia, ${ }^{13}$ China, ${ }^{26}$ Thailand, ${ }^{27}$ Korea, ${ }^{29}$ Belgium, ${ }^{30}$ Greece, ${ }^{31}$ and Ethiopia. ${ }^{4}$ Our present study involved 252 cases with FICB and 256 cases with NB. These studies were all prospective. According to the type of probe, that is, parallel to the inguinal ligament or perpendicular to the inguinal ligament, the FICB technique was categorized into 2 classes: the parallel approach and the perpendicular approach. Four studies used the parallel approach, whereas other studies used the perpendicular approach. The types of LA administered in these studies was either bupivacaine $(n=4)$ or ropivacaine $(\mathrm{n}=3)$. The volumes of the mixture could be divided into 3 categories: $40 \mathrm{~mL}(\mathrm{n}=4), 30 \mathrm{~mL}(\mathrm{n}=2)$, and weight related $(n=1)$. The major characteristics of the eligible publications are reported in Table 1.

\section{Quality assessment}

The mean score of QAS for the 7 studies was 20.9. Among them, 3 studies were ranked "fair" and 4 were ranked "good". The insufficient clinical outcomes is the main item limiting the quality. Because none of the studies was ranked "poor", all the studies were enrolled in the subsequent analysis.

\section{Pain score at 4, 12 , and $24 \mathrm{~h}$ after surgery}

The results of subgroup analysis are shown in Table 2 . The pooled analysis of 4 trials, which included 217 patients, showed that the patients receiving FICB had a lower pain score at $4 \mathrm{~h}$ after surgery $(\mathrm{MD}=-1.17 ; 95 \% \mathrm{CI}=-2.30$ to $-0.05 ; P=0.041$, Figure 3 ) with an obvious heterogeneity $\left(P=0.000, I^{2}=92.3 \%\right)$. The pooled analysis of 5 trials, which included 359 patients, showed that patients receiving FICB

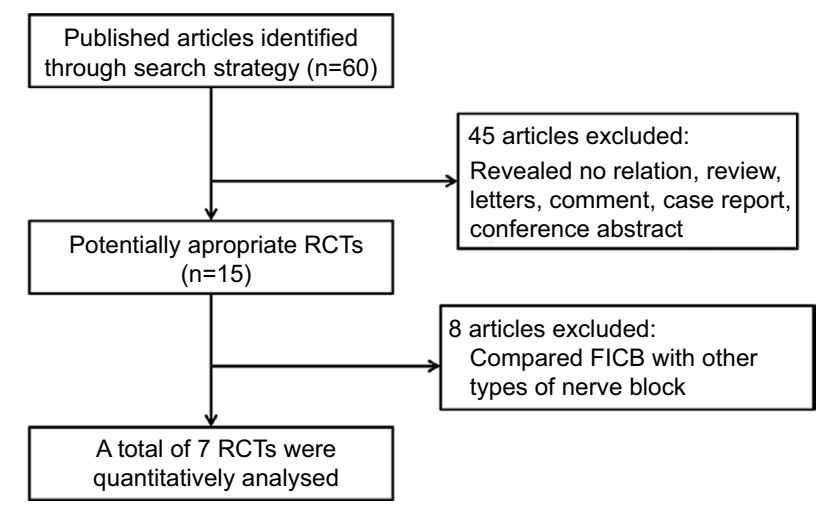

Figure 2 Flow diagram of the study selection process.

Abbreviations: FICB, fascia iliaca compartment block; RCTs, randomized controlled trials. 


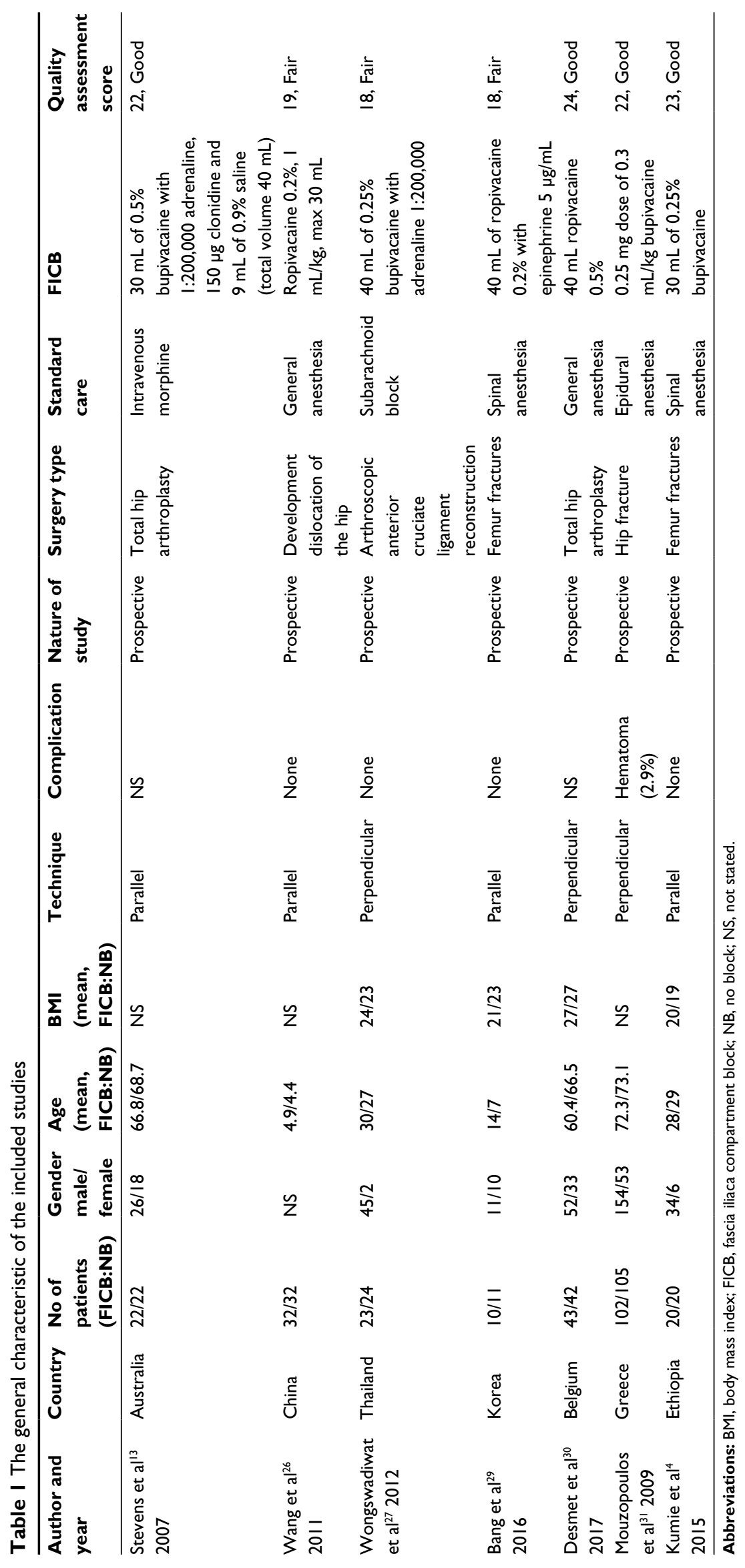


Table 2 Pooled results according to subgroup analysis

\begin{tabular}{|c|c|c|c|c|c|c|c|c|}
\hline \multirow[t]{2}{*}{ Variables } & \multirow[t]{2}{*}{ Studies (n) } & \multirow[t]{2}{*}{ Patients (n) } & \multirow[t]{2}{*}{$P$-value } & \multicolumn{3}{|l|}{ Incidence } & \multirow{2}{*}{$\begin{array}{l}\text { Egger's } \\
\text { test }\end{array}$} & \multirow[t]{2}{*}{ Begg's test } \\
\hline & & & & $\begin{array}{l}\text { MD or RR } \\
(95 \% \mathrm{Cl})\end{array}$ & $\begin{array}{l}\text { Heterogeneity } \\
P \text {-value }\left(I_{2}\right)\end{array}$ & Model & & \\
\hline \multicolumn{9}{|l|}{ Pain score } \\
\hline $4 \mathrm{~h}$ & 4 & 217 & $0.04 I$ & $\begin{array}{l}-1.17 \\
(-2.30 \text { to }-0.05)\end{array}$ & $0.000(92.3)$ & Random & 0.487 & 0.734 \\
\hline $12 \mathrm{~h}$ & 5 & 359 & 0.026 & $\begin{array}{l}-0.4 \mathrm{I} \\
(-0.76 \text { to }-0.05)\end{array}$ & $0.078(52.5)$ & Random & 0.404 & 0.806 \\
\hline $24 \mathrm{~h}$ & 6 & 301 & 0.020 & $\begin{array}{l}-0.96 \\
(-1.77 \text { to }-0.15)\end{array}$ & $0.000(90.1)$ & Random & 0.701 & 0.452 \\
\hline $\begin{array}{l}\text { Morphine } \\
\text { consumption }\end{array}$ & 3 & 176 & 0.022 & $\begin{array}{l}-2.06 \\
(-3.82 \text { to }-0.30)\end{array}$ & $0.000(95.3)$ & Random & 0.093 & 1.000 \\
\hline PONV & 5 & 261 & 0.008 & $\begin{array}{l}0.44(0.24 \text { to } \\
0.80)\end{array}$ & $0.538(0)$ & Fixed & 0.976 & 0.806 \\
\hline
\end{tabular}

Abbreviations: MD, mean difference; PONV, postoperative nausea and vomiting; RR, relative risk.

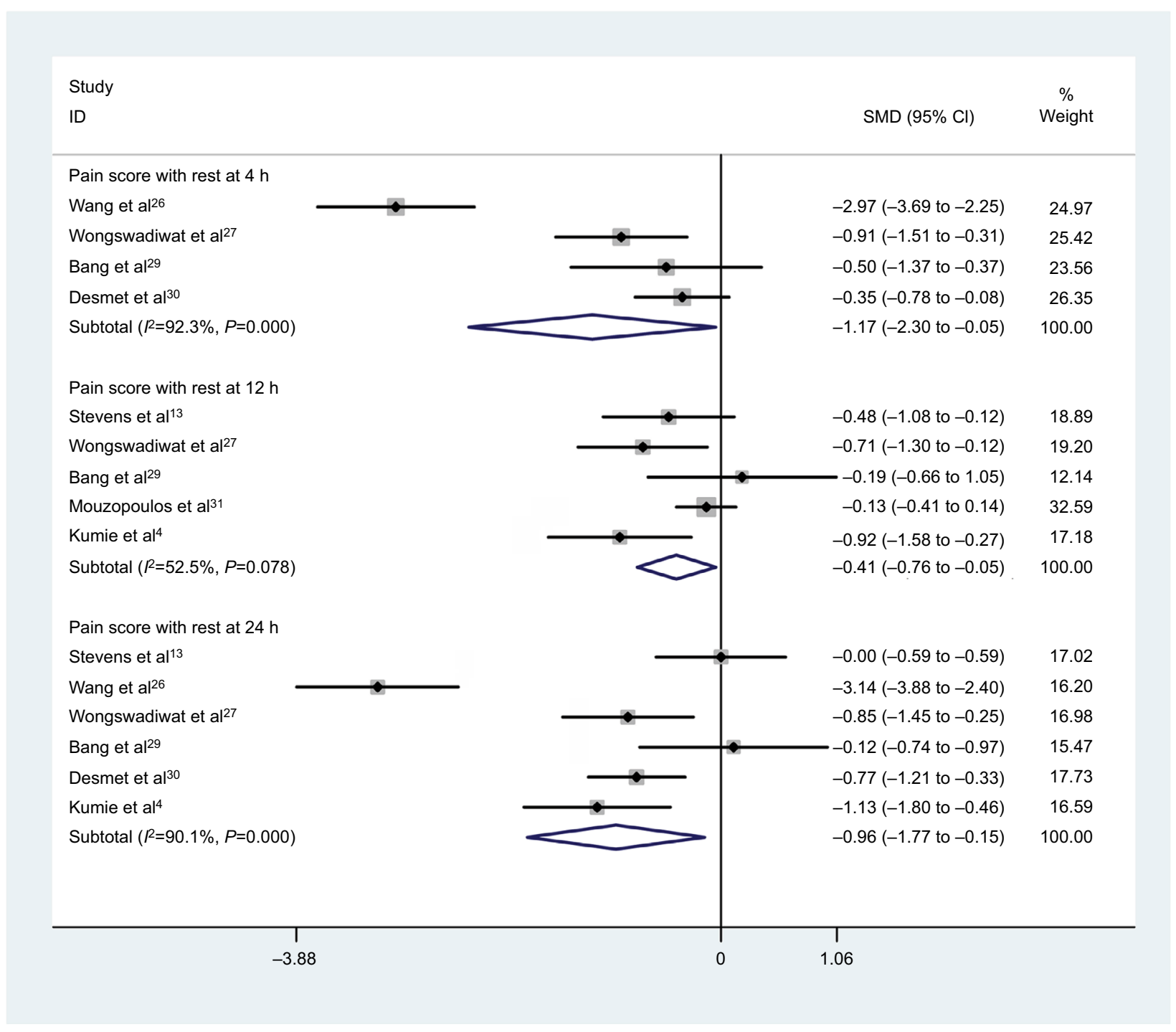

Figure 3 Forest plots of studies comparing FICB and NB for pain score after LLS.

Note: Weights are from random effects analysis.

Abbreviations: FICB, fascia iliaca compartment block; LLS, lower limb surgery; NB, no block; SMD, standard mean difference. 
had a lower pain score at $12 \mathrm{~h}$ after surgery $(\mathrm{MD}=-0.41 ; 95 \%$ $\mathrm{CI}=-0.76$ to $-0.05 ; P=0.026$, Figure 3 ) with no heterogeneity $\left(P=0.078, I^{2}=52.5 \%\right)$. Besides, the pooled analysis of 6 trials, which included 301 patients, showed that patients receiving FICB had a lower pain score at $24 \mathrm{~h}$ after surgery $(\mathrm{MD}=-0.96$; $95 \% \mathrm{CI}=-1.77$ to $-0.15 ; P=0.020$, Figure 3 ) with a significant heterogeneity $\left(P=0.000, I^{2}=90.1 \%\right)$.

The publication bias was not found in this study because the $P$-values of Egger's and Begg's tests were all greater than 0.05 (Table 2). Because of the significant heterogeneity among the studies, we performed a sensitivity analysis and the result pattern was not obviously impacted by any single study (Figure 4).

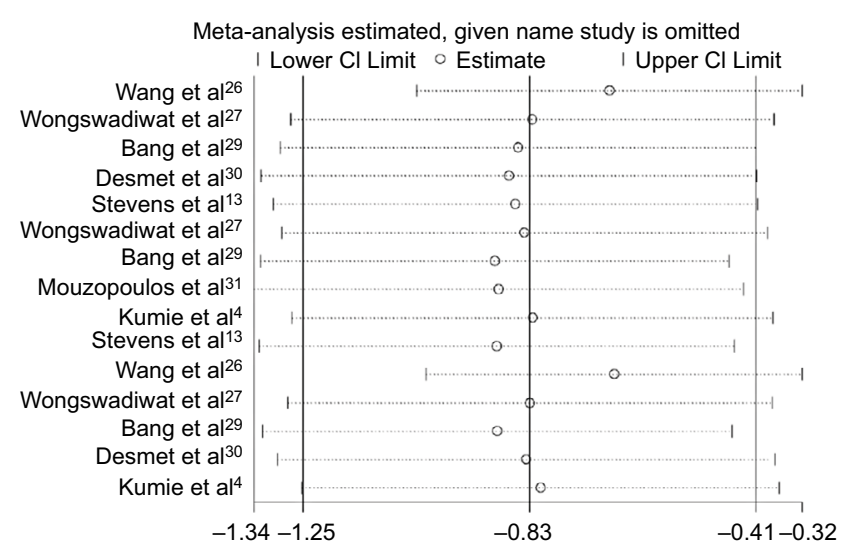

Figure 4 Sensitivity analysis for the pain score after LLS. Abbreviation: LLS, lower limb surgery.
Dosage of morphine at $24 \mathrm{~h}$ after surgery

The pooled analysis of 3 trials, which included 176 patients, showed that the patients receiving FICB had a lower dosage of morphine at $24 \mathrm{~h}$ after surgery $(\mathrm{MD}=-2.06 ; 95 \% \mathrm{CI}=-3.82$ to $-0.30 ; P=0.022$, Figure 5$)$. Moreover, a significant heterogeneity was observed $\left(P=0.000, I^{2}=95.3 \%\right)$.

\section{Postoperative nausea and vomiting}

The occurrence rate of PONV was reported in 5 trials, which included 261 patients. The pooled result showed that FICB helped to reduce the incidence of PONV after $\operatorname{LLS}(\mathrm{RR}=0.44$, $95 \% \mathrm{CI}=0.24-0.80, P=0.008$, Figure 6 ) and there was no obvious statistical heterogeneity $\left(P=0.538, I^{2}=0 \%\right)$.

\section{Discussion}

Pain is a stress response of the body to damage, and is not only a physiological response but also a psychological reaction. Different people have varying susceptibilities to pain. Severe pain can cause patients to experience psychological burden, stress, a restless mood, and affect postoperative exercise and recovery. ${ }^{32}$ LLS usually results in moderate-to-severe pain for the first 24-48 h. Extensive bony and soft tissue damage may be one of the common causes of this pain. Inadequate pain control affects the success of patients' rehabilitation program, and postoperative pain is one of the discharge criteria. The better the pain control is, the more accelerated and satisfactory the rehabilitation program can be.

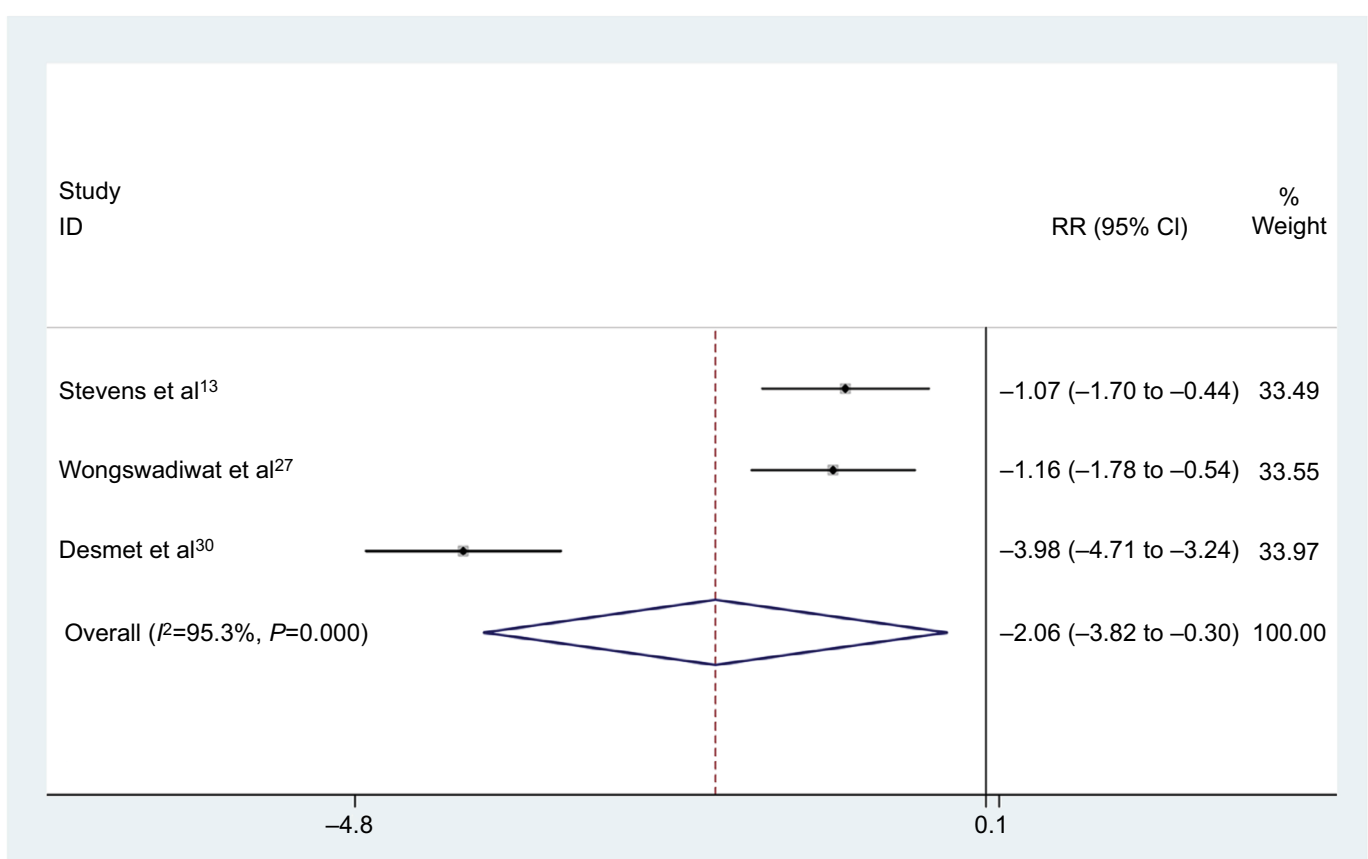

Figure 5 Forest plots of studies comparing fascia iliaca compartment block and no block in terms of morphine consumption at $24 \mathrm{~h}$ after lower limb surgery. Note: Weights are from random effects analysis.

Abbreviation: RR, relative risk. 
Study

ID
Weight

\begin{tabular}{|c|c|c|}
\hline Stevens et al ${ }^{13}$ & $-1.00(-0.34$ to 2.97$)$ & 17.53 \\
\hline Wang et al ${ }^{26}$ & -0.33 (0.01 to 7.89$)$ & 5.26 \\
\hline Wongswadiwat et al ${ }^{27}$ & 0.52 (0.05 to 5.37$)$ & 6.86 \\
\hline Bang et $\mathrm{al}^{29}$ & 0.37 (0.05 to 2.98$)$ & 10.02 \\
\hline Desmet et al ${ }^{30}$ & $0.29(0.12$ to 0.71$)$ & 60.32 \\
\hline Overall $(R=0.0 \%, P=0.538)$ & $0.44(0.24$ to 0.80$)$ & 100.00 \\
\hline 0.009 & 7.9 & \\
\hline
\end{tabular}

Figure 6 Forest plots of studies comparing postoperative nausea and vomiting between the fascia iliaca compartment block and no block groups. Abbreviation: RR, relative risk.

Many methods can provide effective postoperative analgesia for patients receiving LLS, including spinal morphine, ${ }^{33}$ intravenous patient control analgesia, ${ }^{34}$ intra-articular injection of LA or opioid, ${ }^{35}$ femoral nerve block both single shot or continuous infusion via catheter, ${ }^{36}$ ultrasound-guided FICB,${ }^{37}$ and oral analgesic medication (i.e., nonsteroidal anti-inflammatory drugs [NSAIDs], acetaminophen) as multimodal analgesia. ${ }^{38}$ Among these, FICB is injected through the iliac fascia cavity, which is constructed with the fascia as prezone and the iliopsoas as posterior. To a certain extent, the femoral nerve, lateral femoral cutaneous nerve, obturator nerve, and reproductive nerve traverse along the iliac fascia. FICB can result in a statistically significant increase in the incidence of femoral, lateral femoral cutaneous, and obturator nerve block. ${ }^{89}$ Besides, FICB is easy to administer, as it only requires ultrasound guidance. And FICB is a relatively safe anesthesia technique because the needle point is away from the femoral nerve, femoral artery, and femoral vein. ${ }^{39} \mathrm{Nev}-$ ertheless, FICB may also occasionally lead to complications such as hematoma, emphysema, bladder puncture, and nerve damage. Puncture site hematoma and retroperitoneal emphysema of the FICB were reported in few studies, but without any direct adverse effects. ${ }^{4,40}$ Only 1 literature reported a case of bladder puncture caused by FICB, but this patient had a significant hip flexion contracture. ${ }^{41}$ Atchabahian and
Brown $^{42}$ reported the postoperative nerve damage from FICB, but this damage was not persistent. In general, FICB is safe and seems to have few clinical risks. Remarkably, FICB may cause a reflexive knee flexion; therefore, assistive devices such as crutches and temporary knee arthroplasty were recommended to reduce the postoperative risk. ${ }^{43}$

To our knowledge, we are the first to compare the analgesic effect of FICB and NB after LLS using meta-analysis. According to the results of pooled analysis, compared with patients receiving NB, patients receiving FICB suffer less pain at 4,12 , and $24 \mathrm{~h}$ after LLS $(P=0.041, P=0.026$, and $P=0.020$, respectively). This reduction is of clinical importance. At $24 \mathrm{~h}$ after LLS, morphine consumption and incidence of nausea or vomiting in patients receiving FICB were found to be significantly reduced. Ritcey et $\mathrm{al}^{44}$ conducted a systematic review to determine whether regional nerve blocks could reduce pain, the need for parenteral opiates, and complications, compared with standard pain management with opiates, acetaminophen, or NSAIDs. Three studies about FICB were included in their review. ${ }^{3,45,46}$ However, it is difficult to draw a firm conclusion regarding postoperative analgesic effect or other outcomes because of significant bias from the retrospective study and small sample size. Compared with their review, this study included 7 high-quality RCTs and had a larger sample size. Besides, we quantitatively analyzed 
the postoperative analgesic effect and other outcomes of FICB using statistical methods. Therefore, our results might be of more clinical significance.

There are still some limitations in our meta-analysis: First, because of only 7 clinical trials that enrolled 508 patients, the reliability of statistical results might be affected by the small sample size. Second, the pain scoring criteria and the type of LLS in different studies were not uniform, which might also influence the results. Third, there was variability in FICB techniques (probe parallel to the inguinal ligament or perpendicular to the inguinal ligament). Fourth, the type and volume of LA administered in different studies were different.

Compared with NB, FICB is a safe and effective method to reduce the postoperative pain scores, morphine consumption, and the occurrence of PONV in patients after LLS. Furthermore, more RCTs about FICB are needed to identify the optimal technique of FICB.

\section{Disclosure}

The authors report no conflicts of interest in this work.

\section{References}

1. Singelyn FJ, Deyaert M, Joris D, Pendeville E, Gouverneur JM. Effects of intravenous patient-controlled analgesia with morphine, continuous epidural analgesia, and continuous three-in-one block on postoperative pain and knee rehabilitation after unilateral total knee arthroplasty. Anesth Analg. 1998;87(1):88-92.

2. Tovornik M, D'Arcy Y. How to control pain and improve functionality after total joint replacement surgery. Nursing. 2007;37 Suppl Therapy:2-5.

3. Foss NB, Kristensen BB, Bundgaard M, et al. Fascia iliaca compartment blockade for acute pain control in hip fracture patients: a randomized, placebo-controlled trial. Anesthesiology. 2007;106(4):773-778.

4. Kumie FT, Gebremedhn EG, Tawuye HY. Efficacy of fascia iliaca compartment nerve block as part of multimodal analgesia after surgery for femoral bone fracture. World J Emerg Med. 2015;6(2):142-146.

5. Wathen JE, Gao D, Merritt G, Georgopoulos G, Battan FK. A randomized controlled trial comparing a fascia iliaca compartment nerve block to a traditional systemic analgesic for femur fractures in a pediatric emergency department. Ann Emerg Med. 2007;50(2):162-171, 171 e1.

6. Dalens B, Vanneuville G, Tanguy A. Comparison of the fascia iliaca compartment block with the 3-in-1 block in children. Anesth Analg. 1989;69(6):705-713.

7. Beck PR, Nho SJ, Balin J, et al. Postoperative pain management after anterior cruciate ligament reconstruction. J Knee Surg. 2004;17(1):18-23.

8. Swenson JD, Davis JJ, Stream JO, Crim JR, Burks RT, Greis PE. Local anesthetic injection deep to the fascia iliaca at the level of the inguinal ligament: the pattern of distribution and effects on the obturator nerve. J Clin Anesth. 2015;27(8):652-657.

9. Dolan J, Williams A, Murney E, Smith M, Kenny GN. Ultrasound guided fascia iliaca block: a comparison with the loss of resistance technique. Reg Anesth Pain Med. 2008;33(6):526-531.

10. Weller RS. Does fascia iliaca block result in obturator block? Reg Anesth Pain Med. 2009;34(5):524; author reply 524.

11. Capdevila X, Biboulet P, Bouregba M, Barthelet Y, Rubenovitch J, d'Athis F. Comparison of the three-in-one and fascia iliaca compartment blocks in adults: clinical and radiographic analysis. Anesth Analg. 1998;86(5):1039-1044.
12. Deniz S, Atim A, Kurklu M, Çaycı T, Kurt E. Comparison of the postoperative analgesic efficacy of an ultrasound-guided fascia iliaca compartment block versus 3 in 1 block in hip prosthesis surgery. Agri. 2014;26(4):151-157.

13. Stevens M, Harrison G, McGrail M. A modified fascia iliaca compartment block has significant morphine-sparing effect after total hip arthroplasty. Anaesth Intensive Care. 2007;35(6):949-952.

14. Liberati A, Altman DG, Tetzlaff J, et al. The PRISMA statement for reporting systematic reviews and meta-analyzes of studies that evaluate health care interventions: explanation and elaboration. J Clin Epidemiol. 2009;62(10):e1-e34.

15. Stroup DF, Berlin JA, Morton SC, et al. Meta-analysis of observational studies in epidemiology: a proposal for reporting. Meta-analysis Of Observational Studies in Epidemiology (MOOSE) group. JAMA. 2000;283(15):2008-2012.

16. Zhang Q, Thomas SM, Xi S, et al. SRC family kinases mediate epidermal growth factor receptor ligand cleavage, proliferation, and invasion of head and neck cancer cells. Cancer Res. 2004;64(17):6166-6173.

17. Traxler P, Allegrini PR, Brandt R, et al. AEE788: a dual family epidermal growth factor receptor/ErbB2 and vascular endothelial growth factor receptor tyrosine kinase inhibitor with antitumor and antiangiogenic activity. Cancer Res. 2004;64(14):4931-4941.

18. Downs SH, Black N. The feasibility of creating a checklist for the assessment of the methodological quality both of randomised and nonrandomised studies of health care interventions. J Epidemiol Community Health. 1998;52(6):377-384.

19. Deeks JJ, Dinnes J, D'Amico R, et al; International Stroke Trial Collaborative Group; European Carotid Surgery Trial Collaborative Group. Evaluating non-randomised intervention studies. Health Technol Assess. 2003;7(27):iii-x, 1-173.

20. Saunders LD, Soomro GM, Buckingham J, Jamtvedt G, Raina P. Assessing the methodological quality of nonrandomized intervention studies. West J Nurs Res. 2003;25(2):223-237.

21. Chudyk AM, Jutai JW, Petrella RJ, Speechley M. Systematic review of hip fracture rehabilitation practices in the elderly. Arch Phys Med Rehabil. 2009;90(2):246-262.

22. Hooper P, Jutai JW, Strong G, Russell-Minda E. Age-related macular degeneration and low-vision rehabilitation: a systematic review. Can J Ophthalmol. 2008;43(2):180-187.

23. Higgins JP, Thompson SG. Quantifying heterogeneity in a meta-analysis. Stat Med. 2002;21(11):1539-1558.

24. Higgins JP, Thompson SG, Deeks JJ, Altman DG. Measuring inconsistency in meta-analyzes. BMJ. 2003;327(7414):557-560.

25. Duval S, Tweedie R. Trim and fill: a simple funnel-plot-based method of testing and adjusting for publication bias in meta-analysis. Biometrics. 2000;56(2):455-463.

26. Wang G, Wang XL, Li SZ. [Effect of fascia iliaca compartment block with ropivacaine on early analgesia in children with development dislocation of the hip received salter arthroplasty treatment]. Zhonghua Yi Xue Za Zhi. 2011;91(37):2638-2640. Chinese.

27. Wongswadiwat M, Pathanon P, Sriraj W, Yimyaem PR, Bunthaothuk S. Single injection fascia iliaca block for pain control after arthroscopic anterior cruciate ligament reconstruction: a randomized, controlled trial. J Med Assoc Thai. 2012;95(11):1418-1424.

28. Shariat AN, Hadzic A, Xu D, et al. Fascia lliaca block for analgesia after hip arthroplasty: a randomized double-blind, placebo-controlled trial. Reg Anesth Pain Med. 2013;38(3):201-205.

29. Bang S, Chung J, Jeong J, Bak H, Kim D. Efficacy of ultrasound-guided fascia iliaca compartment block after hip hemiarthroplasty: a prospective, randomized trial. Medicine (Baltimore). 2016;95(39):e5018.

30. Desmet M, Vermeylen K, Van Herreweghe I, et al. A longitudinal supra-inguinal fascia iliaca compartment block reduces morphine consumption after total hip arthroplasty. Reg Anesth Pain Med. 2017;42(3):327-333.

31. Mouzopoulos G, Vasiliadis G, Lasanianos N, Nikolaras G, Morakis E, Kaminaris M. Fascia iliaca block prophylaxis for hip fracture patients at risk for delirium: a randomized placebo-controlled study. J Orthop Traumatol. 2009;10(3):127-133. 
32. Palacios-Cena M, Barbero M, Falla D, Ghirlanda F, Arend-Nielsen L, Fernández-de-Las-Peñas C. Pain extent is associated with the emotional and physical burdens of chronic tension-type headache, but not with depression or anxiety. Pain Med. 2017;18(10):2033-2039.

33. Gallardo J, Contreras-Dominguez V, Begazo H, Chávez J, Rodríguez R, Monardes A. [Efficacy of the fascia iliaca compartment block versus continuous epidural infusion for analgesia following total knee replacement surgery]. Rev Esp Anestesiol Reanim. 2011;58(8):493-498. Spanish.

34. Ahiskalioglu EO, Ahiskalioglu A, Aydin P, Yayik AM, Temiz A. Effects of single-dose preemptive intravenous ibuprofen on postoperative opioid consumption and acute pain after laparoscopic cholecystectomy. Medicine (Baltimore). 2017;96(8):e6200.

35. Erdogan MA, Ozgul U, Ucar M, et al. Effect of transversus abdominis plane block in combination with general anesthesia on perioperative opioid consumption, hemodynamics and recovery in living liver donors: the prospective, double-blinded, randomized study. Clin Transplant. 2017;31(4).

36. Yu B, He M, Cai GY, Zou TX, Zhang N. Ultrasound-guided continuous femoral nerve block versus continuous fascia iliaca compartment block for hip replacement in the elderly: a randomized controlled clinical trial (CONSORT). Medicine (Baltimore). 2016;95(42):e5056.

37. Nie H, Yang YX, Wang Y, Liu Y, Zhao B, Luan B. Effects of continuous fascia iliaca compartment blocks for postoperative analgesia in hip fracture patients. Pain Res Manag. 2015;20(4):210-212.

38. Dingemann J, Plewig B, Baumann I, Plinkert PK, Sertel S. Acupuncture in posttonsillectomy pain: a prospective, double-blinded, randomized, controlled trial. HNO. 2017;65(Suppl 1):73-79.
39. Madabushi R, Rajappa GC, Thammanna PP, Iyer SS. Fascia iliaca block versus intravenous fentanyl as an analgesic technique before positioning for spinal anesthesia in patients undergoing surgery for femur fractures-a randomized trial. J Clin Anesth. 2016;35:398-403.

40. Wiberg A, Carapeti E, Greig A. Necrotising fasciitis of the thigh secondary to colonic perforation: the femoral canal as a route for infective spread. J Plast Reconstr Aesthet Surg. 2012;65(12):1731-1733.

41. Blackford D, Westhoffen P. Accidental bladder puncture: a complication of a modified fascia iliaca block. Anaesth Intensive Care. 2009;37(1): 140-141.

42. Atchabahian A, Brown AR. Postoperative neuropathy following fascia iliaca compartment blockade. Anesthesiology. 2001;94(3): 534-536.

43. Hogh A, Dremstrup L, Jensen SS, Lindholt J. Fascia iliaca compartment block performed by junior registrars as a supplement to pre-operative analgesia for patients with hip fracture. Strategies Trauma Limb Reconstr. 2008;3(2):65-70.

44. Ritcey B, Pageau P, Woo MY, Perry JJ. Regional nerve blocks for hip and femoral neck fractures in the emergency department: a systematic review. CJEM. 2016;18(1):37-47.

45. Fujihara Y, Fukunishi S, Nishio S, Miura J, Koyanagi S, Yoshiya S. Fascia iliaca compartment block: its efficacy in pain control for patients with proximal femoral fracture. J Orthop Sci. 2013;18(5):793-797.

46. Godoy Monzon D, Vazquez J, Jauregui JR, Iserson KV. Pain treatment in post-traumatic hip fracture in the elderly: regional block versus. systemic non-steroidal analgesics. Int J Emerg Med. 2010;3(4):321-325.
Journal of Pain Research

\section{Publish your work in this journal}

The Journal of Pain Research is an international, peer reviewed, open access, online journal that welcomes laboratory and clinical findings in the fields of pain research and the prevention and management of pain. Original research, reviews, symposium reports, hypothesis formation and commentaries are all considered for publication

\section{Dovepress}

The manuscript management system is completely online and includes a very quick and fair peer-review system, which is all easy to use. Visit http://www.dovepress.com/testimonials.php to read real quotes from published authors. 